\title{
Influence of Exposure to an Aggressive Environment on Cyclic Fatigue Response and Life of an Alloy Steel
}

\author{
S. Gowda, K. Manigandan, A. Patnaika and T.S. Srivatsan* \\ Department of Mechanical Engineering, The University of Akron, Akron, Ohio 44325, USA
}

Received 20 March 2017; Accepted 28 September 2017

\begin{abstract}
Corrosion or environment-induced degradation often occurs in structural steel as an electrochemical process which leads to gradual loss in mass over a period when subjected to prolonged exposure to an aggressive environment. Immediate effects of this environment-induced degradation, also referred to in industry circles as corrosion, includes a progressive reduction of the cross section, which in turn has a detrimental influence on stiffness and load carrying capacity of the components in a structure, such as a bridge, a stiffened panel or a building. Due to its high strength, low alloy A572 Grade 50 steel is a potentially viable candidate for a wide range of applications in the construction industry. However, like in other high strength alloy steels, A572 is vulnerable to the effects of degradation-induced by the environment owing to its chemical composition. This paper discusses the details of tests conducted to determine the fatigue properties of A572 steel after inducing uniform environment-induced degradation or corrosion. Flat (rectangular dog-bone shaped) specimens, conforming to specifications detailed in ASTM E8 standard, were used in this study. A technique that was developed by the ASTM and General Motors Corporation (GM) [called GMW14872] for a controlled corrosion process based on use of the spray technique was used to induce accelerated corrosion on selected test specimens in an environment chamber. Stress-controlled high cycle fatigue tests were conducted on the corroded test specimens and compared with the asnew, uncorroded counterpart.
\end{abstract}

Keywords: A572 steel; Corrosion; GMW14872; Orientation; Microstructure; Fatigue life; Degradation.

$$
\text { تأثير التعرض لبيئة وعرة على تفاعل الاجهاد الدوري و عمرسبائك الصلب * ك. مانيغاندان، أنيل باتتايك و تس. سريفاتسان }
$$

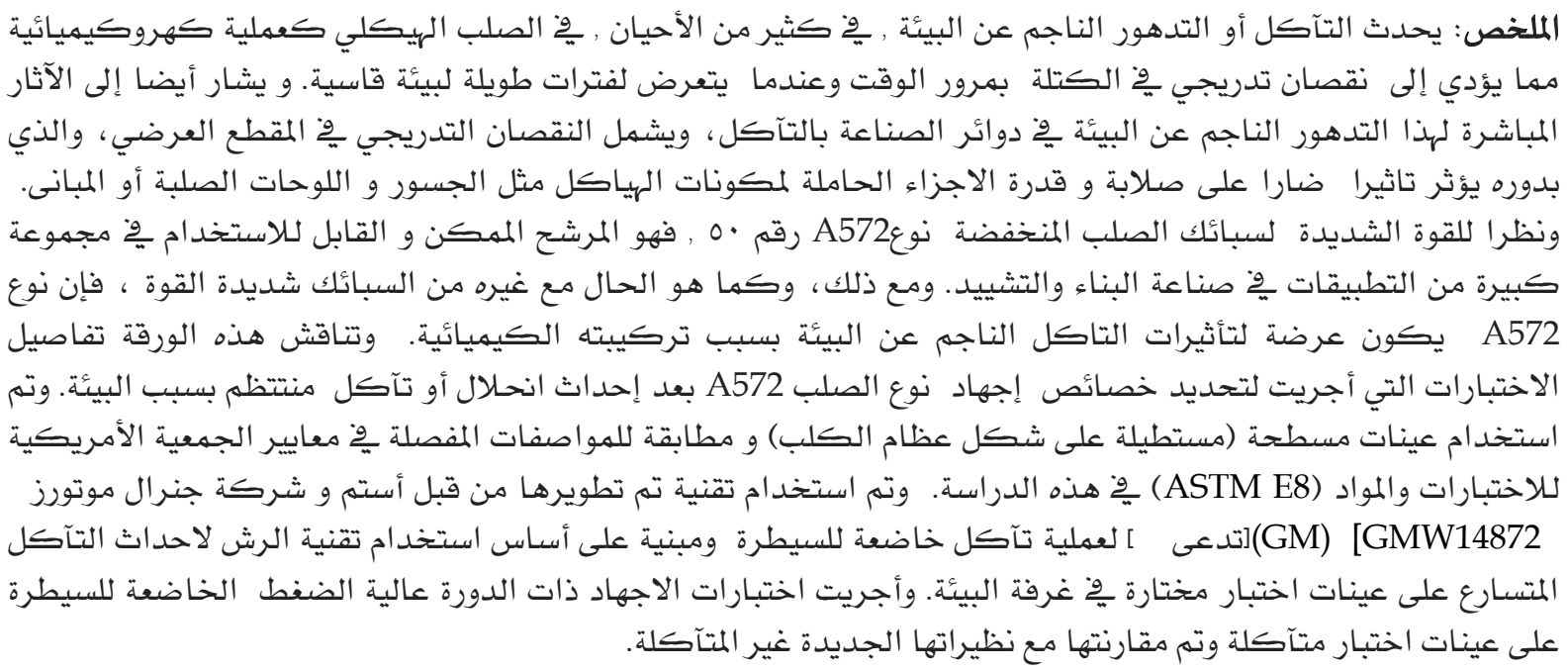

الكلمات المفتاحية: الصلب أ بV ، التآكل، ، والتوجيه، الاجزاء الاجزاء الظاهرة، ،عمر الاجهاد ، التاكل.

* Corresponding author's e-mail: tsrivatsan@uakron.edu 


\section{Introduction}

Based both on economy and strength, structural steel can be safely categorized to be one of the most economically viable and preferentially attractive choice for selection and use in a spectrum of infrastructure-related applications to include buildings, bridges, transportation ways, and even industrial equipment (Banerjee 1965). These steel structures are often built using a combination of various standard shapes, the dimensions of which are both defined and documented by the American Institute of Steel Construction [AISC] (American Institute of Steel Construction 2005) to be wide flanged sections, angled members, channel sections and even hollow structures. Since these steel structures are often exposed to environments spanning a range of aggressiveness, a gradual loss of metal due to environment-induced degradation, referred to in industry relevant circles as corrosion, becomes a critical issue during the service life of a structure. The loss of metal, or metal-based material, results in a progressive decrease in strength of the structure, which eventually leads to failure of the structural element, or structure, and concomitant risk to safety and overall well-being (Banerjee 1965).

Common types of corrosion encountered by steel-based structures include the following: (i) uniform corrosion, (ii) galvanic corrosion, (iii) pitting corrosion, (iv) stress corrosion cracking, and (v) crevice corrosion (Fontana 1986). Upon identification of the type of corrosion it is up to the discretion of the engineer to determine viable ways to either mitigate or totally prevent them from occurring and thereby suppress deterioration and/or degradation. The scope of this research study was limited to evaluating and understanding the uniform corrosion behavior of a high strength alloy steel.

The influence of corrosion in a sodium chloride $(\mathrm{NaCl})$ aqueous solution and cyclic loading is known to affect the long term mechanical properties and cyclic endurance of metallic alloys belonging to both the ferrousbased and non-ferrous-based families (Konda 1979; Xe et al. 2008; Laird and Duquette 1973; Pelloux and Genkin 2008; Plin-Luc et al. 2010; Ebara et al. 1980; McAdam 1927; Devos et al. 2006; Metals Handbook: Properties and Selection 1990; May et al. 2012 and Liu et al. 2011). The mechanical response of structural steels is governed by the conjoint and mutually interactive influences of chemical composition, history of processing used to engineer the starting material, intrinsic microstructural effects and test temperature. Structural ASTM A572 grade 50 steel was chosen for this research study with the primary purpose of determining the influence of corrosion on cyclic stresscontrolled high cycle fatigue response. The steel plates used in this study were manufactured and provided by Alro steel (Akron, $\mathrm{OH}$ ). This alloy steel is a high performance structural steel based on its chemical composition and mechanical properties (Metals Handbook: Properties and Selection 1990). Specific details pertaining to secondary processing treatment given to the as-provided steel stock were proprietary by the manufacturer. The minimum strength allowed for ASTM A572 grade 50 steel is yield strength [ $\sigma_{\mathrm{ys}}$ ] of $345 \mathrm{MPa}$ and ultimate tensile strength [ $\sigma_{\mathrm{UTS}}$ ] of $450 \mathrm{MPa}$.

General, or uniform corrosion, is the most prevalent form of corrosion resulting in overall loss of surface material, which culminates in progressive thinning of the structural member. This type of corrosion often accounts for the largest percentage of corrosioninduced damage experienced by steel structures that are often exposed to aggressive aqueous environment and/or gaseous environment (Fontana 1986 and Kondo 1979). In fact, general or uniform corrosion has been regarded as one of the most easily identifiable form of corrosion due to the overall nature of the corrosion process. Since there does occur a uniform loss of material, the corrosion rate is also considered to be uniform. Besides an observable loss in mass there also occurs a degradation in strength and a noticeable drop or decrease in ductility of the chosen material. The magnitude of degradation experienced by the material being proportional to the extent and severity of corrosion resulting because of materialenvironment interaction. Uniform corrosion has been regarded by researchers to be less dangerous and/or damaging type of corrosion due to its easily identifiable nature (Fontana 1986; Laird and Duquette 1973; Pelloux and Genkin 2008; Plin-Luc et al. 2010; Ebara et al. 1980 and McAdam 1927).

One of the simplest examples of uniform corrosion is the formation of an oxide product that protects the steel from weathering. A newly weathered steel is generally coated with very fine in size mill scale that gradually flakes off because of continued weathering action and corrosion. This in turn tends to expose the base metal to the aggressive environment. A gradual progression of the corrosion process occurs until 
such time the surface is covered with its own corrosion product. Presence of corrosion product on the surface does tend to reduce, or decelerate, the rate of corrosion by forming a protective barrier between the metal and the environment (Devos et al. 2006 and Metals Handbook: Properties and Selection 1990). Uniform corrosion has been observed to occur in bridges made from structural steel where in structural components often having a large surface area are easily prone to either attack or oxidation because of exposure to an aggressive environment (Devos et al. 2006 and Metals Handbook: Properties and Selection 1990). Usually, the small pits on the surface of the steel tend to grow and eventually coalesce. This can safely be categorized as uniform corrosion rather than pitting corrosion.

The effect of corrosion on cyclic stresscontrolled high cycle fatigue response of a high strength martensitic stainless steel, which is available for use in aeronautical applications was shown by May and co-workers (May et al. (2012). Based on fractographic observations and interpretations coupled with results obtained from mechanical tests, the mechanisms for fatigue crack initiation in the environments of laboratory air and aqueous sodium chloride $(\mathrm{NaCl})$ solution were recorded. It was found that repeated rupture of the "local" passive film was largely responsible for favoring the occurrence of crack initiation during cyclic loading. The film experiences repeatedly rupturing by strain in the material that is induced by the applied cyclic stress during cyclic fatigue testing. This then causes the material, i.e. steel, to experience increased environment-induced attack at the 'local' level.

In another study, the initiation of fine microscopic cracks was found to accelerate by preferential corrosion at locations of high "local" plastic strain of the high strength steel 38CrMoAl. The effect of using an accelerated pre-corrosion salt spray environment on fatigue behavior was investigated. The fatigue life response characteristics of the pre-corroded test specimens were studied using statistical probability methods, and both mathematical expectations and standard tolerances for fatigue life of the material following different precorrosion times were determined. It was concluded from this study that presence of corrosion-induced pits accelerated the fatigue crack initiation and exacerbated fatigue crack growth while concurrently reducing fatigue life of the material.
The objective of this research paper is to present and discuss the results of a recent study aimed at examining the influence of exposure to an aggressive aqueous environment on cyclic fatigue response and life of high strength alloy steel A572 and thereby assess the severity of degradation in fatigue life arising from exposure to an aggressive environment.

\section{Experimental Procedures}

\subsection{Corrosion [Procedure: GMW14872]}

The GMW14872 (GMW14872: Cyclic Corrosion Laboratory Test 2006) procedure is an accelerated laboratory corrosion test for evaluating the corrosion properties of metals. Concentration of salt solution, temperature, and humidity are important factors that must be considered in studying the accelerated corrosion behavior of metals. The GM14872 was categorized to be an effective method for evaluating different types of corrosion ranging from general (uniform), to galvanic and including crevice corrosion. The individual parameters, such as: (i) concentration of salt solution, (ii) test temperature, and (iii) humidity, can be varied with the primary purpose of achieving a desired level of damage due to corrosion.

The test is run in terms of a cycle. Each cycle represents 24 hours ( 1 day) of testing. The required loss in mass experienced by a coupon is obtained for a targeted exposure time. Often in this test, 15 cycles of exposure were carried out, which is divided into 3 categories. This cycle test also considers the weekends.

\subsubsection{Preparation of Salt Solution}

The testing solution is a combination of Sodium Chloride $(\mathrm{NaCl})$, Calcium Chloride $\left(\mathrm{CaCl}_{2}\right)$ and Sodium Bicarbonate $\left(\mathrm{NaHCO}_{3}\right)$. The sodium chloride is of the reagent type or food grade. Calcium chloride is also of reagent type and sodium bicarbonate can be either baking soda type or comparable product type. Both $\mathrm{CaCl}_{2}$ and $\mathrm{NaHCO}_{3}$ chemicals were dissolved separately in water, and then gradually added to solution of sodium chloride.

\subsubsection{Initial Cleaning of the Test Coupon}

1. The coupons were first washed using a required amount of acetone with the primary purpose of removing any dye or paint on the surface of the metal. This was followed by: (i) rinsing with distilled water, 
(ii) drying the coupon with a lint free towel, and (iii) gentle scrubbing.

2. The samples then had their surfaces touched up using 600-grit emery paper with the purpose of removing any oil, mill scale and other corrosion products adhering to the surface. Subsequently, they were labeled, taped, thickness measured, and precision weighed.

3. It is critical that all forming or preservation oils/lubes be removed prior to exposure to facilitate the occurrence of general/uniform corrosion of the coupon. This process was aided by using a commercial grade degreaser prior to cleaning the surface with either methanol or acetone.

\subsubsection{Post Corrosion Cleaning}

According to procedures detailed in ASTM standard (ASTM G1-03 2011), Standard Practice for Preparing, Cleaning and Evaluation Corrosion Test Specimens, this essentially involved cleaning of the corrosion products resulting as a direct consequence of the corrosion process. These can be categorized to be (i) mechanical, (ii) chemical, and (iii) electrolytic. However, the scope of this research is limited to the chemical method used for purpose of removal of corrosion products.

An ideal procedure should remove only the corrosion products and should not result in removal of the base metal. To determine the loss in mass experienced by the base metal when removing the corrosion-induced products, duplicate un-corroded control specimens were also cleaned using the same procedure that was used for the test specimens. By weighing the control specimen, both before and after cleaning, the extent of loss in mass, experienced by the metal as a direct consequence of cleaning can be utilized to correct for the mass loss resulting due to environment-induced corrosion.

Chemical procedures involved immersion of the corrosion test specimen in a specific solution that is designed to remove the corrosion products with minimal dissolution of any base metal. A few procedures are listed in ASTM G1-03 (2011). The exact choice of the chemical procedure to be used can be categorized to be one of trial and error with the primary objective of establishing the most effective method for a specific metal and type of product scale due to corrosion. In this study, the C 3.2 corrosion procedure was used for purposes of cleaning. A description of this cleaning procedure is summarized in Table 1. The effect of different cleaning procedures on tensile strength of cylindrical samples [ASTM E8] is shown in Fig. 1. From this graph, it can be inferred that the ASTM C 3.2 cleaning procedure for purpose of removing corrosion products from the surface of a steel specimen is not a true representation of the cleaning process as it is not only removes rust on the surface but also a considerable amount of the base metal resulting in a noticeable drop in tensile strength of the test specimen. Instead, the ASTM C 3.1, also called as Clarke's solution was used for removing corrosion products from the surface of the test specimen as it does not adversely influence the base metal.

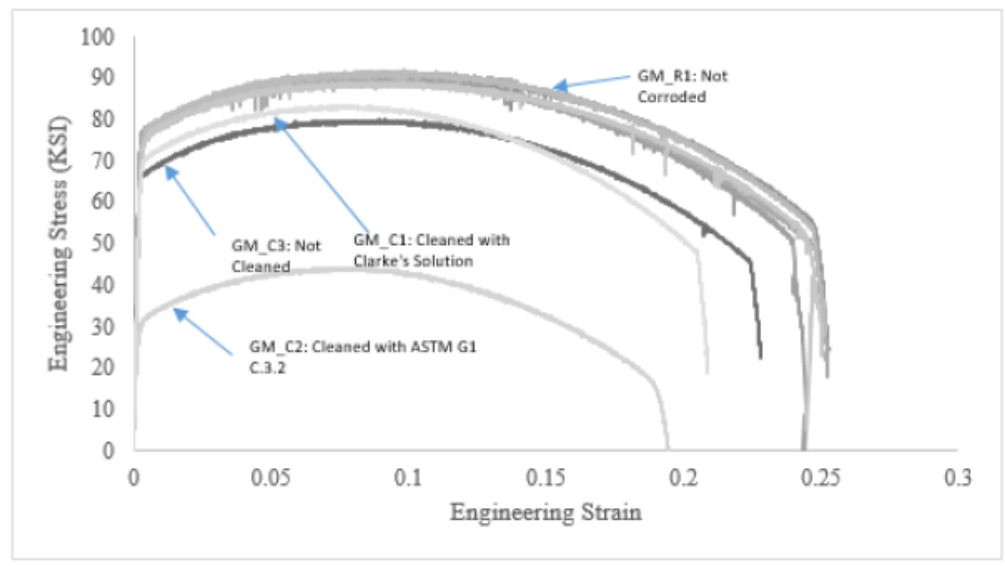

Figure 1. Effect of ASTM cleaning procedures on the tensile strength of A572 steel. 
Table 1. Chemical cleaning procedures for removal of corrosion products according to ASTM G1 [0]. C 3.1 is adopted for this study.

\begin{tabular}{|c|c|c|c|c|c|}
\hline Designation & Material & Solution & Time & Temperature & Remarks \\
\hline C 3.2 & Iron and Steel & $\begin{array}{l}50 \mathrm{~g} \mathrm{NaOH} \\
200 \mathrm{~g} \text { granulated } \\
\text { zinc or zinc chips } \\
\text { Reagent water to } \\
\text { make } 1000 \mathrm{~mL}\end{array}$ & $\begin{array}{c}30 \text { to } 40 \\
\text { mins }\end{array}$ & 80 to $90^{\circ} \mathrm{C}$ & $\begin{array}{l}\text { Caution should be } \\
\text { exercised in the } \\
\text { use of any zinc } \\
\text { dust since sponta- } \\
\text { neous ignition up- } \\
\text { on exposure to air } \\
\text { can occur. }\end{array}$ \\
\hline C 3.1 & Iron and Steel & $\begin{array}{l}1000 \mathrm{ml} \mathrm{HCl}, 20 \mathrm{~g} \\
\text { antimony } \\
\text { trioxide, } \\
\text { stannous } \\
\begin{array}{l}\text { chloride, } \\
\text { NaOH }\end{array}\end{array}$ & $\begin{array}{l}1 \text { to } 25 \\
\text { mins }\end{array}$ & 20 to $25^{\circ} \mathrm{C}$ & $\begin{array}{l}\text { Solution should be } \\
\text { vigorously stirred } \\
\text { or specimen sho- } \\
\text { uld be brushed. } \\
\text { Longer times may } \\
\text { be required in } \\
\text { certain instances. }\end{array}$ \\
\hline
\end{tabular}

\subsubsection{Preparation of Coupon Rack}

Prior to the initiation of the test; a coupon rack to hold sufficient coupons was prepared. For this test, two types of racks were used. The rack for the rectangular coupons had an angled slot to ensure that the test solution stays on the surface without having to run down, which aids in the occurrence of uniform corrosion of the metal surface. The rack for the cylindrical specimens had grooved slots for facilitating exposure of test specimen to the aggressive aqueous environment.

\subsubsection{Process of Testing}

The GMW14872 (GMW14872: Cyclic Corrosion Laboratory Test 2006) corrosion cycle was repeated every day until requirements for test exposure were met. The testing was continued through the weekends for decreasing the test time provided the number of cycles $(\mathrm{N})$ and mass loss requirements were met.

For each salt mist application, a spray apparatus was used to mist the test samples and coupons until all areas were thoroughly wet and/or dripping. The quantity of spray applied was adequate to visibly rinse away any salt accumulation or residue left from the previous spray. At the end of each cycle ( 24 hours), the coupons were: (i) removed from the test chamber, (ii) washed with de-ionized water (DI water), (iii) sprayed with the test solution, and (iv) put back into the chamber. The different stages [Ambient Stage, Humid Stage and Dry stage) were automatically controlled by the test chamber.

\subsection{Mechanical Testing}

The tensile and cyclic fatigue tests were performed on a fully automated, servohydraulic INSTRON testing machine equipped with a $100 \mathrm{kN}$ load cell. All the tests were performed in the room temperature, laboratory air environment $\left(\mathrm{T}=27^{\circ} \mathrm{C}\right.$, Relative Humidity of 55 pct.). An axial $12.5 \mathrm{~mm}$ gage length clip-on type extensometer was attached to the test specimen at the gage section using elastic bands. The stress and strain measurements parallel to the load line and resultant mechanical properties were provided as an output by the control unit of the servo hydraulic test machine.

The stress amplitude-controlled high cycle fatigue tests were performed using a sinusoidal waveform and in conformance with procedures outlined in ASTM: E466-07 [17]. Cyclic fatigue tests were conducted over a range of stress amplitudes $(\Delta \sigma / 2)$, at a constant frequency of 5 $\mathrm{Hz}$ and at a load ratio of 0.1 , to determine the fatigue life $\left(\mathrm{N}_{\mathrm{f}}\right)$. From the test results, the following relationships were established:

a) Variation of fatigue life $\left(\mathrm{N}_{\mathrm{f}}\right)$ with stress amplitude $(\Delta \sigma / 2)$.

b) Variation of fatigue life $\left(\mathrm{N}_{\mathrm{f}}\right)$ with maximum elastic strain $\left(\sigma_{\max } / \mathrm{E}\right)$. 


\section{Results and Discussion}

\subsection{Initial Microstructure}

Optical microstructure of the chosen ASTM A572 sample (Chemical composition given in Table 2) is as shown in Fig. 2 for both the longitudinal (L) and transverse (T) orientations. The observed microstructure is typical of high carbon, low alloy content steel. The primary micro-constituent is the carbon depleted white region that is referred to as ferrite. The grains are distinct with well-defined grain boundaries, small and non-uniform in shape. The secondphase particles primarily the carbides were dispersed randomly through the microstructure. The presence and morphology of the ferrite micro-constituent is governed both by chemical composition and the processing techniques, both primary and secondary, used to engineer this steel. These intrinsic features, namely: the size and morphology of the ferrite micro constituent along with randomly distributed carbide particles, are an important factor that determines the hardness, tensile properties and cyclic fatigue response, quantified in terms of fatigue life.

\subsection{Tensile Properties}

The tensile properties for both the longitudinal $(\mathrm{L})$ and transverse $(\mathrm{T})$ orientations for the chosen structural steel, for the two different exposure times, i.e. 7 days and 14 days, are summarized in Table 3. Results reported are the mean values based on duplicate tests.

For testing in laboratory air and at the two chosen exposure times; that is, 7-day exposure and 14-day exposure, the yield strength and ultimate tensile strength was consistent, i.e. well within the range of 5-10 percent, in both the longitudinal (L) and transverse $(\mathrm{T})$ orientation. In both orientations, i.e. longitudinal and transverse, the tensile strength was noticeably higher than the yield strength indicating the occurrence of strain hardening beyond yield. Upon exposure for time periods of 7-days and 14-days to an aggressive aqueous environment, the tensile yield strength and ultimate tensile strength of the chosen alloy steel revealed an observable decrease in comparison to values for the test specimen in laboratory air $\left(27^{\circ} \mathrm{C}\right)$ and no exposure to an aggressive environment.

For a fixed exposure time to the aggressive aqueous environment the elongation was consistent in both the longitudinal (L) and transverse $(\mathrm{T})$ orientations. Time of exposure to the aggressive aqueous environment was observed to have minimal influence on ductility, quantified by elongation over a gage length of $12.5 \mathrm{~mm}$, of the chosen alloy steel. Reduction in test specimen cross-section area, another measure of ductility, was identical in both the longitudinal (L) and transverse $(\mathrm{T})$ orientations, for a given exposure time to the environment.
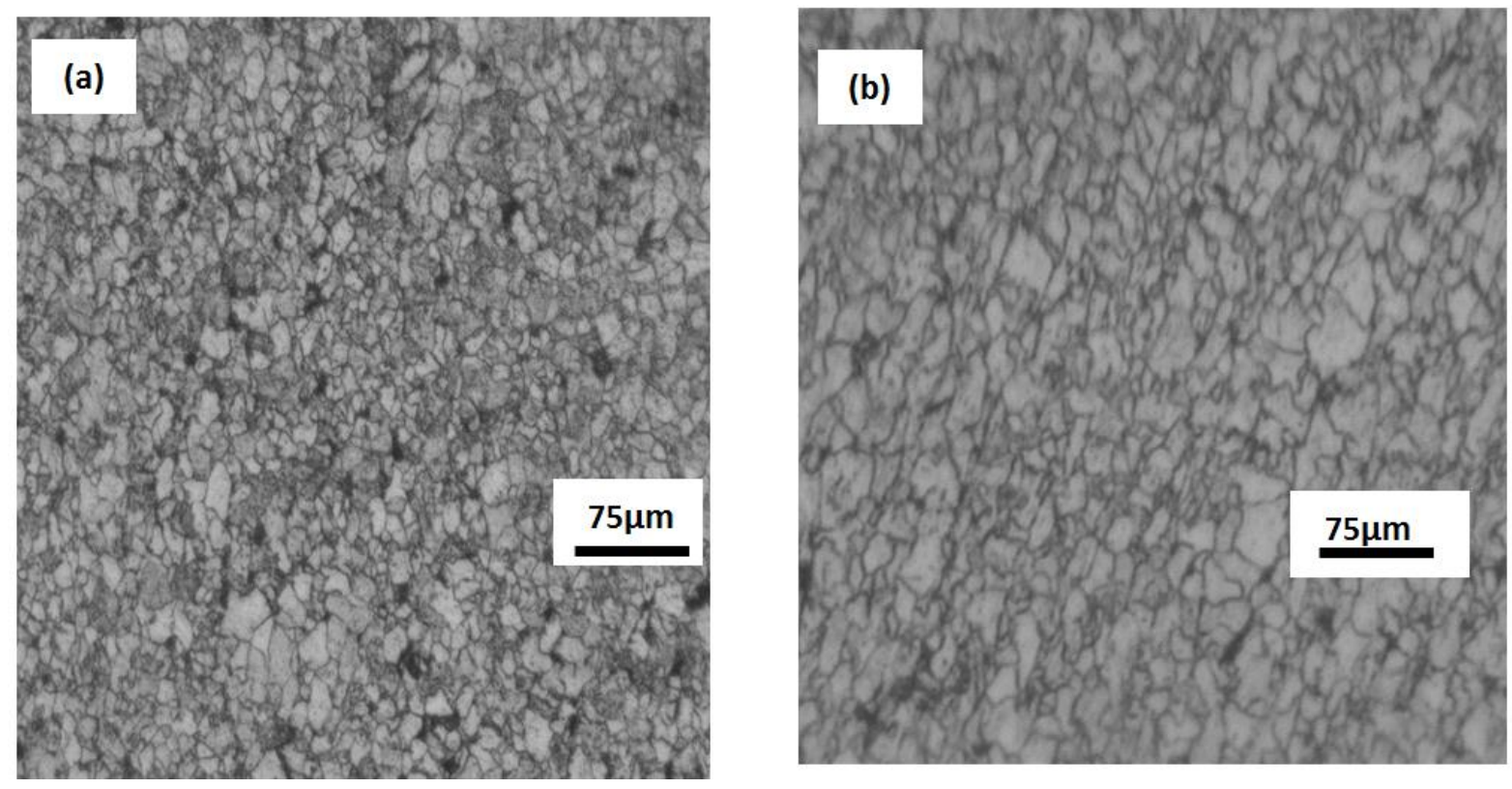

Figure 2. Optical micrographs showing microstructure of A572 steel in the two orientations: (a) Longitudinal at 200X, and (b) Transverse at $200 \mathrm{X}$. 
Further, the reduction in test specimen crosssection area was observed to noticeably decrease for both the longitudinal (L) and transverse $(\mathrm{T})$ orientations with an increase in time of exposure to the aggressive aqueous environment upon comparing with the values obtained for the tests done in room temperature $\left(27^{\circ} \mathrm{C}\right)$, laboratory air environment.

Table 2. Nominal chemical composition of the chosen alloy steel A572 (in weight percent)

\begin{tabular}{lllll}
\hline & C & Mn & P & S \\
\hline A572 & 0.25 & 1.35 & 0.04 & 0.05 \\
\hline
\end{tabular}

Table 3. Uniaxial tensile properties of A572 alloy steel for the different conditions.

\begin{tabular}{|c|c|c|c|c|c|c|c|c|c|}
\hline \multirow{2}{*}{$\begin{array}{l}\text { Exposure } \\
\text { Condition }\end{array}$} & \multirow[t]{2}{*}{ Orientation } & \multicolumn{2}{|c|}{$\begin{array}{l}\text { Elastic } \\
\text { Modulus }\end{array}$} & \multicolumn{2}{|c|}{$\begin{array}{l}\text { Yield } \\
\text { Strength }\end{array}$} & \multicolumn{2}{|c|}{ UTS } & \multirow{2}{*}{$\begin{array}{l}\text { Elongation } \\
(\%)\end{array}$} & \multirow{2}{*}{$\begin{array}{l}\text { Reduction } \\
\text { in Area } \\
(\%)\end{array}$} \\
\hline & & Ksi & GPa & Ksi & MPa & Ksi & MPa & & \\
\hline \multirow{2}{*}{$\begin{array}{c}\text { No } \\
\text { Exposure }\end{array}$} & Longitudinal & 30457 & 210 & 68 & 471 & 73 & 505 & 27 & 41 \\
\hline & Transverse & 30312 & 209 & 65 & 447 & 75 & 516 & 28 & 41 \\
\hline \multirow{2}{*}{$\begin{array}{c}\text { 7-Day } \\
\text { Exposure }\end{array}$} & Longitudinal & 30167 & 208 & 64 & 441 & 68 & 473 & 25 & 33 \\
\hline & Transverse & 30457 & 210 & 58 & 405 & 68 & 474 & 26 & 33 \\
\hline \multirow{2}{*}{$\begin{array}{l}\text { 14-Day } \\
\text { Exposure }\end{array}$} & Longitudinal & 30167 & 208 & 53 & 365 & 58 & 403 & 26 & 23 \\
\hline & Transverse & 30167 & 208 & 56 & 387 & 66 & 459 & 23 & 23 \\
\hline
\end{tabular}

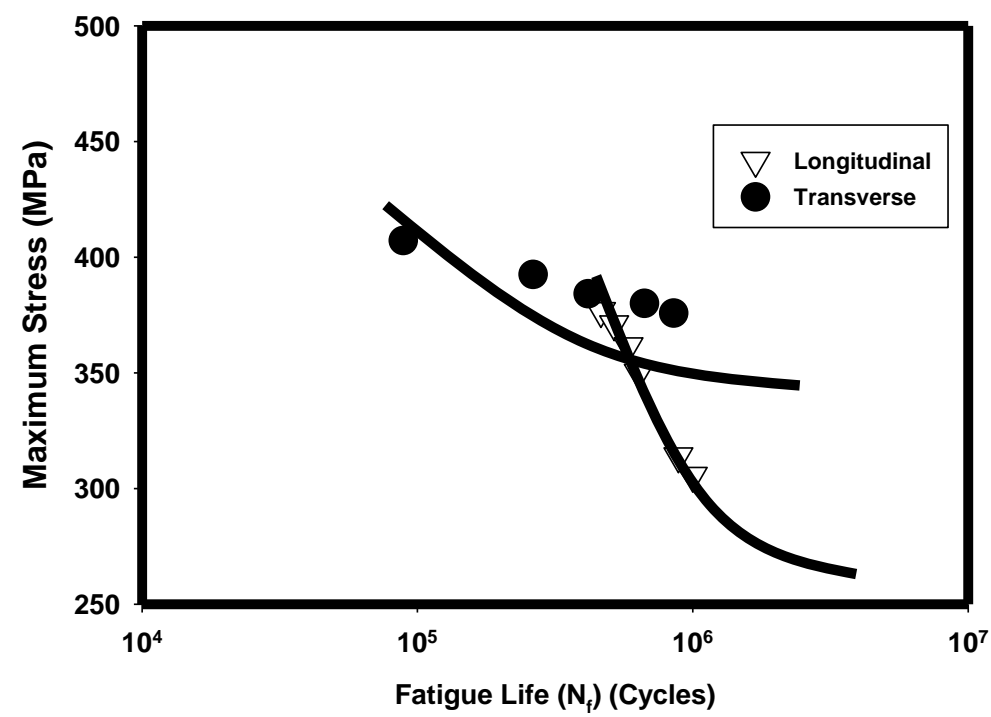

Figure 3. Influence of test specimen orientation on variation of maximum stress $\left(\sigma_{\max }\right)$ with fatigue life $\left(\mathrm{N}_{\mathrm{f}}\right)$ for $\mathrm{A} 572$ steel when cyclically deformed for as-new specimens and at a load ratio of 0.1 . 


\subsection{Cyclic Stress Amplitude Controlled Fatigue}

\subsubsection{As-received, Unexposed Test Samples}

The test results of the stress amplitudecontrolled cyclic fatigue tests for both the longitudinal (L) and transverse (T) orientations in the room temperature $\left(27^{\circ} \mathrm{C}\right)$ environment are shown in Fig. 3 as the variation of cyclic fatigue life $\left(\mathrm{N}_{\mathrm{f}}\right)$ with maximum stress $\left(\sigma_{\max }\right)$. The curves in this figure reveal a gradual increase in cyclic fatigue life $\left(\mathrm{N}_{\mathrm{f}}\right)$ with a decrease in maximum stress $\left(\sigma_{\max }\right)$. This is very much in conformance with the trend shown by most ferrous alloys and their composite counterparts. To have a better understanding of the variation of maximum stress $\left(\sigma_{\max }\right)$ with cyclic fatigue life $\left(\mathrm{N}_{\mathrm{f}}\right.$ in the two chosen orientations [longitudinal (L) and transverse (T)] the variation of maximum stress with fatigue life $\left[\mathrm{N}_{\mathrm{f}}\right]$ is plotted as the variation of maximum elastic strain $\left[\sigma_{\max }\right.$ $/ E]$ with fatigue life $\left[\mathrm{N}_{\mathrm{f}}\right]$. This is shown in Fig. 4 and reveals a linear trend. At equivalent values of maximum elastic strain $\left[\sigma_{\max } / E\right]$ the transverse $(\mathrm{T})$ orientation had higher cyclic fatigue life than the longitudinal (L) orientation. This clearly reveals the specific role and contribution of intrinsic microstructural features and resultant intrinsic microstructural effects in governing stress versus fatigue life $\left(\mathrm{N}_{\mathrm{f}}\right)$ response of the un-exposed test samples as a function of test specimen orientation.

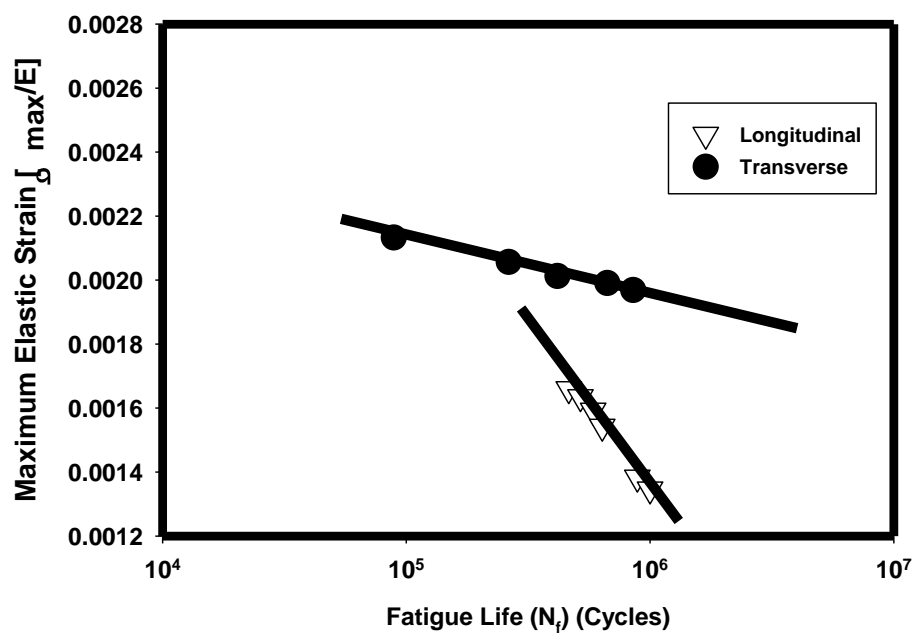

Figure 4. Influence of test specimen orientation on variation of maximum elastic strain $\left(\sigma_{\max } / E\right)$ with fatigue life $\left(\mathrm{N}_{\mathrm{f}}\right)$ for $\mathrm{A} 572$ steel when cyclically deformed for as-new specimens and at a load ratio of 0.1

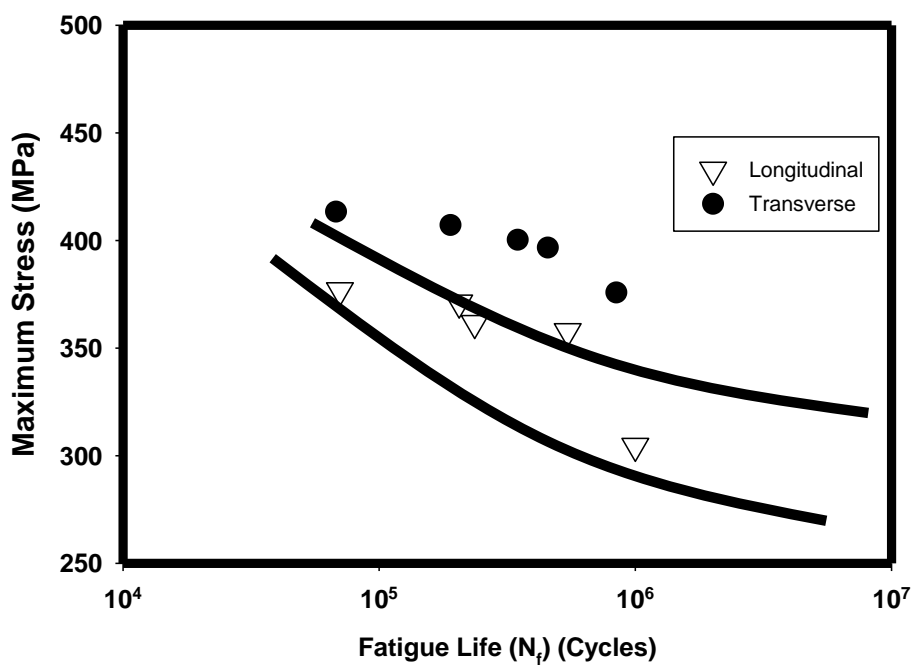

Figure 5. Influence of test specimen orientation on variation of max stress $\left(\sigma_{\max }\right)$ with fatigue life $\left(\mathrm{N}_{\mathrm{f}}\right)$ for the A572 steel when cyclically deformed at a load ratio of 0.1 following 7 -days of exposure to environment. 


\subsubsection{Exposure for 7 Days to the Aqueous Environment}

The variation of maximum stress $\left(\sigma_{\max }\right)$ with cyclic fatigue life $\left(\mathrm{N}_{\mathrm{f}}\right)$ is shown in Fig. 5 for the test samples that were cyclically deformed following seven days of exposure to the aggressive aqueous environment. This behavior or trend shown is quite like behavior observed for the as-received, unexposed text samples. The cyclic fatigue life $\left(\mathrm{N}_{\mathrm{f}}\right)$ increased with a decrease in maximum stress $\left(\sigma_{\max }\right)$. At equivalent values of maximum stress, the fatigue life of the test specimen taken from the longitudinal (L) orientation was less than the transverse (T) counterpart (Fig. 5). Variation of maximum elastic $[\sigma \max / E]$ strain with cyclic fatigue life $\left(\mathrm{N}_{\mathrm{f}}\right)$, shown in Fig. 6, reveals a linear trend, and at equivalent values of maximum elastic strain the longitudinal (L) orientation was inferior to the transverse $(\mathrm{T})$ orientation by more than one-order of magnitude.

\subsubsection{Exposure for 14 days to Aggressive Aqueous Environment}

The test results for samples that were exposed for full 14 days to the aggressive aqueous environment are shown in Figs. 7 and 8. Variation of maximum stress with cyclic fatigue life $\left(\mathrm{N}_{\mathrm{f}}\right)$ is as shown in Fig. 7 . The chosen steel following prolonged exposed to an aggressive environment reveals a pattern of increasing fatigue life with a decrease in maximum stress, a trend shown by most other ferrous alloys and to even their composite counterparts. At near equivalent values of the maximum stress, the test specimens taken from the longitudinal $(\mathrm{L})$ orientation revealed inferior fatigue life $\left(\mathrm{N}_{\mathrm{f}}\right)$ when compared to the test specimens taken from the transverse orientation (T). From a design engineering perspective, the variation of maximum elastic strain $\left[\sigma_{\max } / E\right]$ with fatigue life is linear and at equivalent

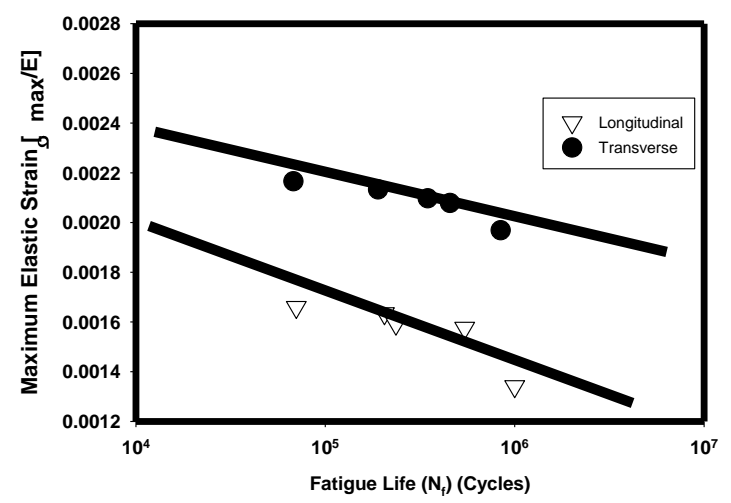

Figure 6. Influence of test specimen orientation on variation of maximum elastic strain $\left(\sigma_{\max } / \mathrm{E}\right)$ with fatigue life $\left(\mathrm{N}_{\mathrm{f}}\right)$ for the A572 steel when cyclically deformed at a load ratio of 0.1 following 7-days of exposure to the environment.

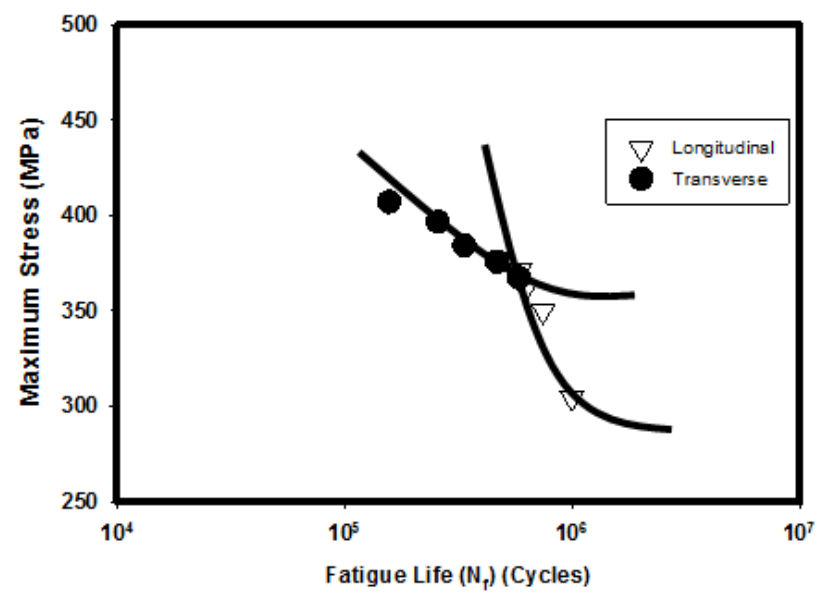

Figure 7. Influence of test specimen orientation on variation of max stress $\left(\sigma_{\max }\right)$ with fatigue life $\left(\mathrm{N}_{\mathrm{f}}\right)$ forthe A572 steel when cyclically deformed at a load ratio of 0.1 following 14-days of exposure to the environment. 
values of maximum elastic strain the test samples from the longitudinal (L) orientation revealed at least an order of magnitude inferior fatigue life when compared with the samples taken from the transverse $(\mathrm{T})$ orientation (Fig. 8).

Influence of time of exposure to aggressive aqueous environment for test specimens taken from longitudinal (L) orientation of the asprovided plate stock is shown in Fig. 9 as the variation of maximum stress $(\mathrm{MPa})$ with fatigue life $\left(\mathrm{N}_{\mathrm{f}}\right)$. Minimal to no difference is observed for the trend shown by the unexposed samples and the test samples exposed for 14 full days to the aggressive aqueous environment. However, the test specimens that were exposed for seven days to the aggressive environment revealed an observable decrease in cyclic fatigue life $\left(\mathrm{N}_{\mathrm{f}}\right)$ at equivalent values of maximum stress. This can be ascribed to the formation and presence of a thin layer of corrosion deposits on the surface of the test sample coupled with the occurrence and presence of fine microscopic pits that are detrimental to crack initiation during continued cyclic loading.

Influence of time of exposure to aggressive aqueous environment on test specimens prepared from the transverse $(\mathrm{T})$ orientation of the as-provided alloy steel (A572) stock is shown in Fig. 10. This figure reveals that at equivalent values of maximum stress the test specimens that were exposed for seven days to the environment revealed marginally better cyclic fatigue life $\left(\mathrm{N}_{\mathrm{f}}\right)$ when compared to the unexposed counterpart. This is attributed to the protective nature of the corrosion-induced deposits on the sample surface upon exposure to an aggressive environment. However, an increase in exposure time of the test specimen to the aggressive aqueous environment was observed to be detrimental to cyclic high cycle fatigue resistance by way of decreased fatigue life. At equivalent values of maximum stress the decrease in cyclic fatigue life increased at the lower values of maximum stress and resultant enhanced fatigue life $\left(\mathrm{N}_{\mathrm{f}}\right)$. This can essentially be attributed to rupture of the brittle corrosion deposits that form on the sample surface under the extrinsic influence of sustained cyclic loading.

\subsection{Viable Mechanisms Governing Failure at the Fine Microscopic Level} In this research paper, an attempt has been made to present and briefly discuss the conjoint and mutually interactive influences of time of exposure to an aggressive environment and test specimen orientation on high cycle fatigue response and life of ASTM A572 high strength alloy steel. The observed fracture behavior is quantified based on both the macroscopic mode and the underlying mechanisms governing deformation and fracture occurring at the fine microscopic level.

Under conditions of cyclic loading in tensiontension [positive load ratio ( $R$ ) of 0.1] the introduction and presence of dislocations in the metal matrix coupled with their gradual build up, or accumulation, at locations of:

(i) The grain boundaries.

(ii) Interfaces of the soft and plastically deforming ferrite matrix and the hard and elastically deforming second-phase, which in this case is predominantly pearlite, and

(iii) Presence of other hard and elastically deforming second-phase particles, namely the carbide particles, that are randomly distributed through the microstructure, are conducive for an early initiation of fine microscopic voids during cyclic deformation.

The formation of voids is favored to occur when the local strain caused by the gradual build-up of dislocations at the interfaces of the soft and plastically deforming metal matrix with the hard and elastically deforming secondphase particle reaches a critical value. The conditions prevailing for an early initiation of fine microscopic voids become appropriate upon the occurrence of yielding at the "local" level. With continued cyclic loading, a few of the hard and essentially elastically deforming second-phase particles tend to easily fail by cracking because their intrinsic brittleness when compared one-on-one with the soft and plastically deforming metal matrix, i.e., ferrite micro-constituent. Since gradual growth of the fine microscopic voids coupled with extension of the crack is favored to occur at the prevailing high local stress intensities, the presence of several microscopic and macroscopic voids contribute to decrease in fatigue life $\left(\mathrm{N}_{\mathrm{f}}\right)$ of the test specimen [18]. 


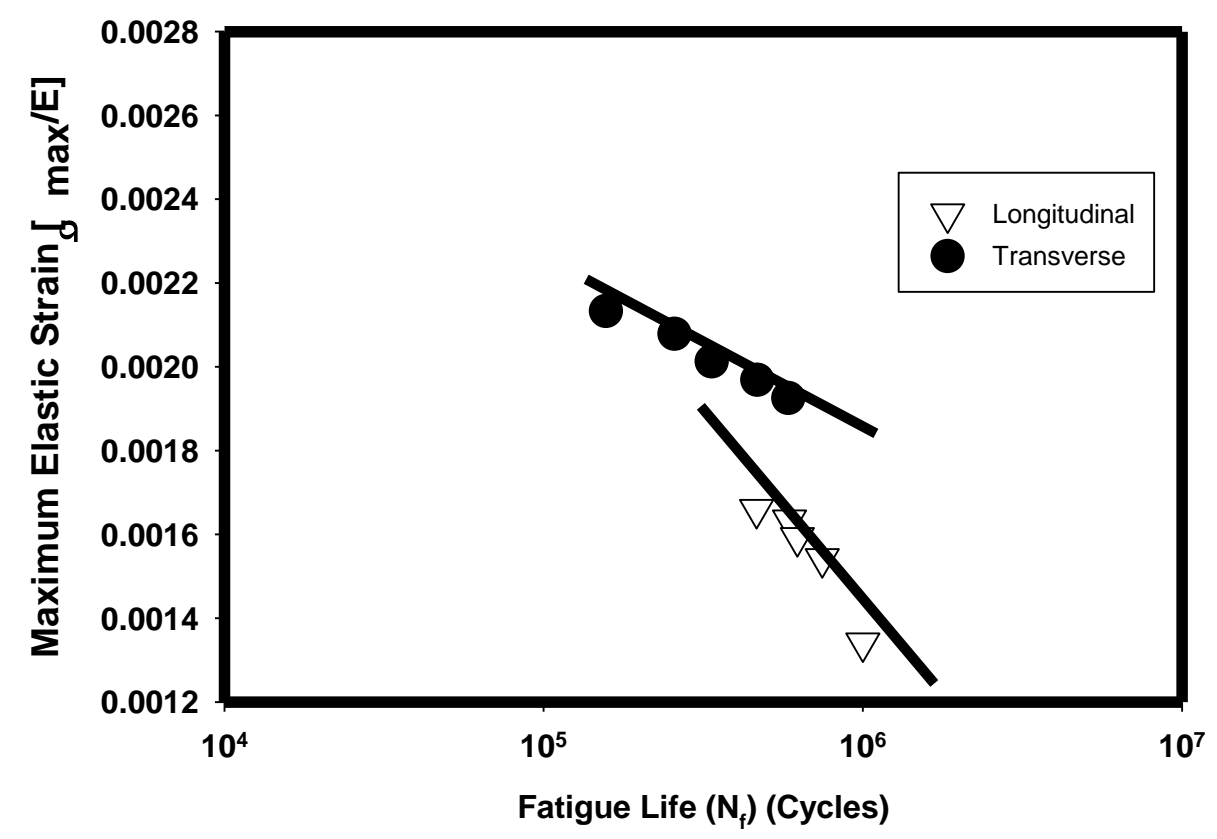

Figure 8. Influence of test specimen orientation on variation of maximum elastic strain $\left(\sigma_{\max } / \mathrm{E}\right)$ with fatigue life $\left(\mathrm{N}_{\mathrm{f}}\right)$ for the A572 steel when cyclically deformed at a load ratio of 0.1following 14-days exposure to the environment.

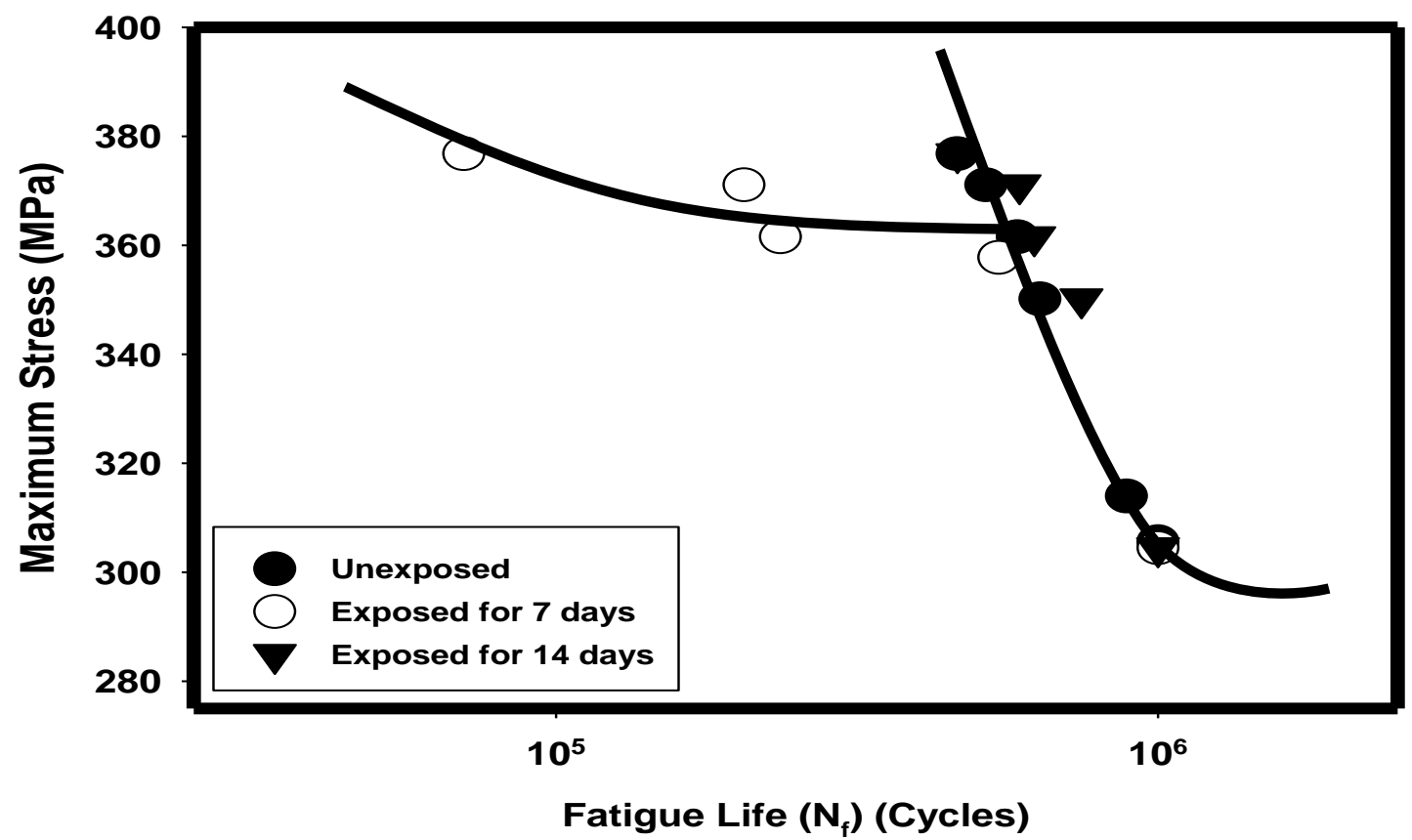

Figure 9. Influence of tine of exposure to aggressive aqueous environment on the variation of maximum stress $(\mathrm{MPa})$ with cyclic fatigue life $\left(\mathrm{N}_{\mathrm{f}}\right)$ for test specimens taken from the longitudinal orientation of the chosen A572 steel. 


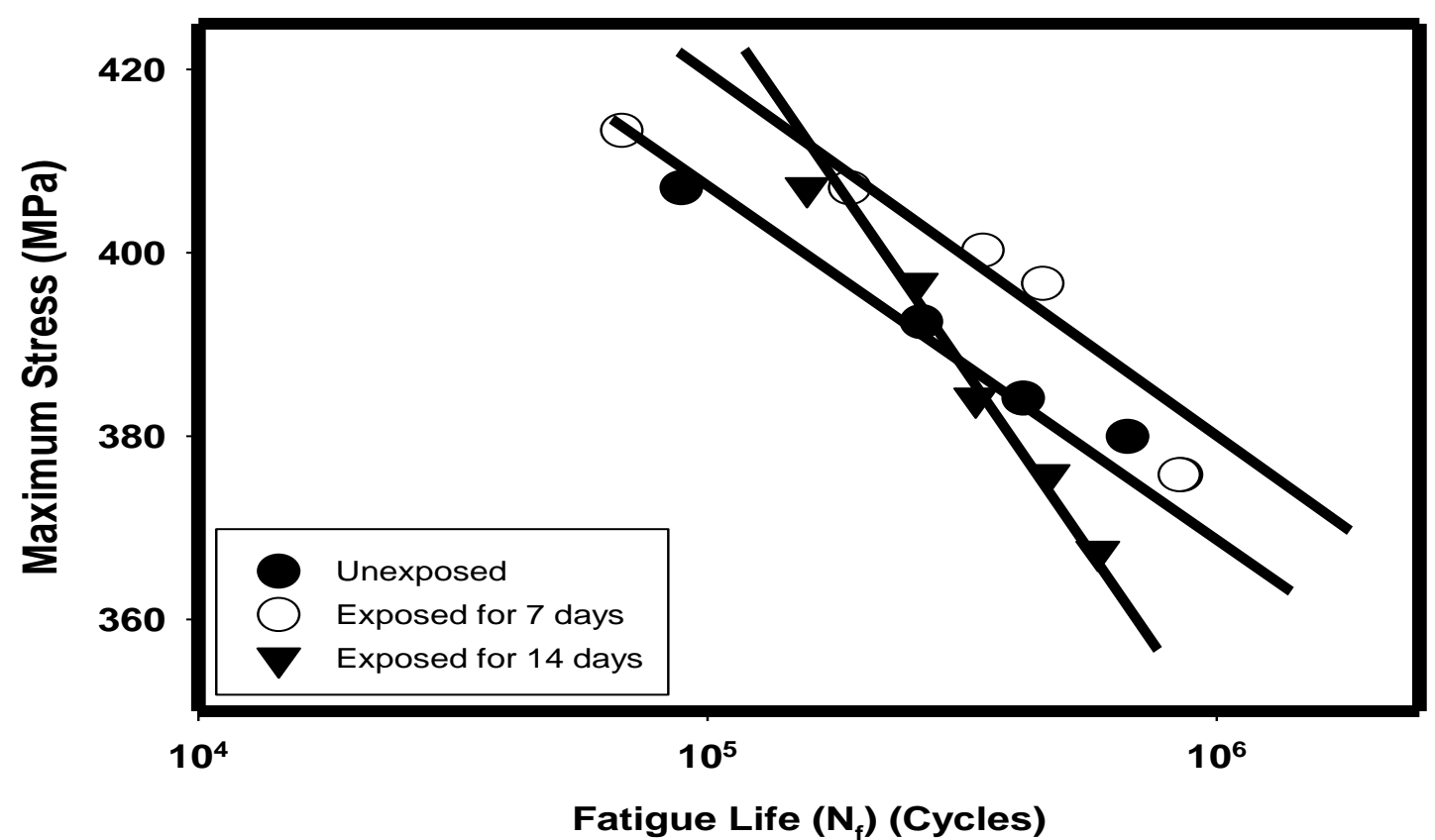

Figure 10. Influence of tine of exposure to aggressive aqueous environment on the variation of maximum stress $(\mathrm{MPa})$ with cyclic fatigue life $\left(\mathrm{N}_{\mathrm{f}}\right)$ for test specimens taken from the transverse (T) orientation of the chosen A572 steel.

\subsection{Potential Future Area of Research Study}

Based entirely on the experiments executed systematically with precision and the results obtained, there now exists a thought by the authors to pursue numerical modeling through finite element analysis the prediction of behavior or response of these structures when exposed to aggressive environments for prolonged periods of times extending far and beyond 14-day exposure. Based on this preliminary experimental study we plan on using the numerical approach to provide valuable information on structural response when exposed to aggressive environments for an extended period.

\section{Conclusion}

This study was undertaken with the objective of understanding the specific role of time of exposure to an aggressive environment and test specimen orientation on tensile properties, cyclic high cycle fatigue response and final fracture behavior of the high strength low alloy steel A572 following are the key findings.

1. Light optical micrographs reveal a microstructure that is rich in the microconstituent ferrite, i.e. the carbon depleted region. The grains are small and of varying shape. The second-phase particles are randomly dispersed through the microstructure.

2. At a given value of maximum stress, test specimens taken from the longitudinal [L] orientation had noticeably lower cyclic fatigue life than the test specimens machined from the transverse [T] orientation. This is attributed to the role and/or contribution from intrinsic microstructural effects during cyclic loading.

3. The noticeable Inferior high cycle fatigue resistance for the test specimens of the alloy taken from the longitudinal [L] orientation when compared one-on-one with the transverse [T] counterpart is evident at all values of the ratio of maximum stress and maximum elastic strain for the chosen alloy steel (A572) in the specific orientation.

4. For test specimens taken from both the longitudinal [L] and transverse [T] orientations, that were exposed for 168 hours (7 days) to the environment prior to cyclic fatigue testing, the test specimens taken from the longitudinal [L] orientation of the alloy steel plate had an order of magnitude lower fatigue life than the test specimens prepared from the transverse orientation.

5. For test specimens of alloy steel A572 taken from both the longitudinal [L] and 
transverse $[\mathrm{T}]$ orientations and exposed for 14 full days to the aggressive environment prior to cyclic fatigue testing, both orientations show a trend of increase in fatigue life with decrease in maximum stress.

\section{Conflict of Interest}

The authors declares no conflicts of interest.

\section{Funding}

The research work presented in this paper was partially funded by the DoD Technical Corrosion Collaboration (TCC), U.S. DoD Office of Corrosion Policy and Oversight. The research was administered by the U.S. Construction Engineering Research Laboratory under agreement number FY12 W9132T-11-C-0035.

\section{References}

American Institute of Steel Construction (2005), (AISC): Steel Construction Manual in Unified 13th Edition, Chicago, IL, USA.

ASTM E466 (2011), Standard test method for conducting constant amplitude axial fatigue tests on metallic materials. ASTM, American Society for Testing and Materials, Philadelphia, PA, USA.

ASTM G1-03 (2011), Standard practice for preparing, cleaning and evaluating corrosion test specimens. American Society for Testing and Materials, Philadelphia, PA, USA.

Bajer AJ, Laura EJ, Wei RP (1965), Structure and properties of ultrahigh strength steels. ASTM, STP 370, American Society for Testing and Materials 3-14.

Banerjee BR (1965), Structure and properties of ultrahigh strength steels, ASTM, STP 370, American Society for Testing and Materials, Philadelphia, PA, USA. 94-109.

Devos O, Gabrielli G, Tribollet B (2006), Simultaneous EIS and in situ microscope observation on partially blocked electrode application to scale electrodeposition. Electrochemical Acta, 51: 1413-1422.

Ebara R, Yamada Y, Goto Y (1980), Corrosion fatigue behavior of $13 \mathrm{Cr}$ stainless steel and
Ti-6Al-4V ultrasonic frequency. Fatigue ultrasonore, The Minerals, Metals and Materials Society (TMS), Warrendale, PA, USA (1980).

Fatigue Strength of Martensitic Stainless Steel X12CrNiMoV12-3. International Journal of Fatigue (doi: http: // dx.doi.org / 10.1016 / j.ijfatigue.2012.09.018.

Fontana MG (1986), Corrosion engineering, McGraw-Hill Publishers.

GMW14872 (2006), Cyclic corrosion laboratory test. General Motors Corporation, Michigan, USA.

Kondo Y (1979), Prediction of fatigue crack initiation life based on pit growth. Corrosion 45: 7-11.

Laird C, Duquette DJ (1973), Mechanisms of fatigue crack nucleation. In Corrosion fatigue: chemistry, mechanics and microstructure, [Editors: O. Devereux, A.J. McEvily and R.W. Stachle], National Association Corrosion Engineering (NACE) - 2 88.

May ME, Palin-Luc T, Saintier N, Devos O, (2012), Effect of corrosion on the high cycle fatigue strength of martensitic stainless steel $\mathrm{X} 12 \mathrm{CrNiMoV12}-3$. International Journal of Fatigue (2012), doi: http: // dx.doi.org / 10.1016/j.ijfatigue.2012.09.018.

McAdam DJ (1927), Corrosion fatigue of metals. Journal Transaction American Society Steel Treat, 11: 355-79.

Metals Handbook: Properties and Selection (1990), Classification and designation of carbon and low alloy steels. Tenth Edition, ASM International, Materials Park, Ohio, USA.

Palin-Luc T, Pérez-Mora R, Bathias C, Domínguez G, Paris PC, Luis Aran J (2010), "Fatigue crack initiation and growth on a steel in the very high cycle regime with sea water corrosion. Engineering Fracture Mechanics 77: 1953-1962.

Pelloux R, Genkin JM (2008), Chapitre 10: Fatigue-corrosion", in "Fatigue des matériaux et des structures" (editors: C. Bathias and A. Pineau), 2: 141-152.

Xu S, Wu XQ, Han EH, Ke W, Katada Y (2008), Crack initiation mechanisms for lowcycle fatigue of type 316Ti stainless steel in High temperature water. Materials Science and Engineering 490: 16-25. 